\title{
Interactive comment on "Sparse 3D reflection seismic survey for deep-targeting iron-oxide deposits and their host rocks, Ludvika Mines-Sweden" by Alireza Malehmir et al.
}

\section{Anonymous Referee \#2}

Received and published: 10 December 2020

This manuscript is well written, it can be accepted for publications only subject to minor revisions (1) The abstract should be prepared more succinctly, in particular, it is unnecessary to introduce the parameters for seismic data acquisition in so many details. (2) Line 25. What do you indicate for $10 \mathrm{Mt}$ additional resources? Iron ? How did you estimate this potential source? Please indicate the grade of this ore deposit used in the estimate. (3) To be outspoken, I did not see significant improvements of 3D survey compared to 2D survey in Figure 14. Could you please explain this improvement better? 